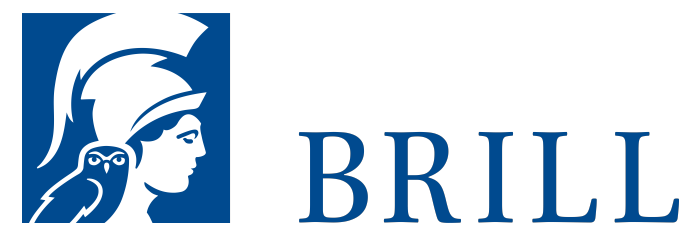

\title{
Zufallsbefunde aus bildgebenden Verfahren in populationsbasierter Forschung
}

Eine empirisch-ethische Untersuchung

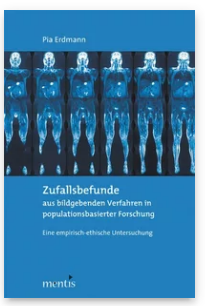

Author: Pia Erdmann

Das Bewusstsein dafür, dass mit Zufallsbefunden, d.h. nichtintendierten Befunden aus medizinischen Untersuchungen, vielschichtige ethische Herausforderungen einhergehen können, hat in den letzten Jahren zugenommen. Dennoch sind Entscheidungen hinsichtlich eines ethisch verantwortlichen Umgangs mit Zufallsbefunden nach wie vor mit großen Unsicherheiten behaftet: Der einschlägige ethische Regulierungsstand bleibt zum Teil vage, die Perspektive der Betroffenen selbst weitgehend unberücksichtigt. Die vorliegende empirisch-ethische Studie untersucht vor diesem Hintergrund am Beispiel von Zufallsbefunden aus einer zu epidemiologischen Forschungszwecken durchgeführten Ganzkörper-MRT-Untersuchung, welche Auswirkungen Zufallsbefunde auf die betroffenen StudienteilnehmerInnen haben können. Die Ergebnisse einer quantitativen und qualitativen Untersuchung einerseits sowie die Analyse des gegenwärtigen ethischen Regulierungsstandes und ein kontraktualistisch begründetes forschungs-ethisches Normenset andererseits werden für einen Abgleich zwischen dem forschungs-ethisch Gebotenen (Sollen) und dem empirisch zugänglich werdenden Ist-Stand (Sein) herangezogen.

Pages: 206

Seiten

Language:

German

Subjects:

General,

Philosophy

Publisher: Brill | mentis

E-Book (PDF)

Released online:

o1 Jan 2015

ISBN: 978-3-

95743-987-1

List price

Paperback

Publication date:

o1 Jan 2015

ISBN: 978-3-

89785-070-5

List price 
For more information see brill.com

Order information: Order online at brill.com +44330 333 0049 | customerservices@brill.com Submission information: brill.com/authors

Titles published by Brill | Fink, Brill | mentis or Brill | Schöningh: +49(o)715413279216| brill@brocom.de 